International Journal of Dental Research, $5(x)(2017) 93-97$
International Journal of Dental Research
Website: $\begin{gathered}\text { www. sciencepubco.com/index.php/IJDR } \\ \text { doi: } 10.14419 / \text { ijdr.v5i2.7475 } \\ \text { Research paper }\end{gathered}$
RPC

\title{
Habits- A contemporary review
}

\author{
Deepak D R ${ }^{1 *}$, Manu Shankar², Karthika B Nair ${ }^{3}$ \\ ${ }^{1}$ Dr.DEEPAK D R, junior resident department of orthodontics $k v g$ dental college \\ ${ }^{2}$ Dr MANU SHANKAR, junior resident department of orthodontics kvg dentalcollege \\ ${ }^{3} \mathrm{Dr}$ KARTHIKA B NAIR junior resident department of paedodontics sri sankara dental college \\ *Corresponding author E-mail:deepakdr2001@gmail.com
}

\begin{abstract}
Although oral habits are being dealt by dentist especially by Pedodontist and orthodontist since long time, but till today this particular abnormal/normal entity is not fully known. Time-to-Time various hypothesis \& explanations have been given by various authors but none of it specifically delineate the habits those which are normal for a particular age group and others, which are deleterious to stomatognathic system. The main reason for this difficulty is that a habit may be a part of normal development, a symptom associated with deep-rooted Psychological disturbance or a habit may be a result of abnormal facial growth. Though it is difficult to delineate it, but it is important to have differentiation of abnormal from normal because If normal development get disturbed unknowingly and at the same time If abnormal growth or underlying psychological cause let continue without interfering at proper time/age it will lead to long lasting effect on stomatognathic system its growth \& development and psychological development of child.
\end{abstract}

Keywords: Habits ; Mastication; Respiration; Speech; Thumb sucking

\section{Introduction}

Habits are learned patterns of muscle contraction of a very complex nature. Certain habits serve as stimuli to normal growth of jaw for example normal lip action and mastication. Abnormal habits, which may interfere with the regular pattern of facial growth, must be differentiated from the desired normal habits that are a part of normal oropharyngeal function and thus play an important role in craniofacial growth and occlusal physiology (Brash $\mathrm{J}, 1929$ ) [1]. As the mouth is the primary and permanent location for expression of emotions and even is a source of relief of passion and anxiety in both children and adults, stimulation of this region with tongue, finger, nail or cigarette can be a palliative action (Bear PN, Lestor M, 1987) [2]. Deleterious habitual patterns of muscle behavior often are associated with perverted or impeded osseous growth, tooth malposition, disturbed breathing habits, difficulties in speech, upset balance in the facial musculature and psychological problems. William James, the eminent psychologist wrote, an acquired habit, from a psychological point of view, is nothing but a new pathway of discharge formed in the brain, by which certain incoming currents ever after tends to escape. Therefore, one cannot correct malocclusion without involvement in such reflex activities.

Oral habits could be divided into 2 main groups:

1) Acquired oral habits: Include those behaviours which are learned and could be stopped easily when the child grows up (Finn SB, 1998) [3].

2) Compulsive oral habits: Consist of those behaviours which are fixed in child and when emotional pressures are intolerable for the child, he or she can feel safety with this habit and preventing the child from these habits make him or her anxious and worried(Finn SB, 1998) [3]. 


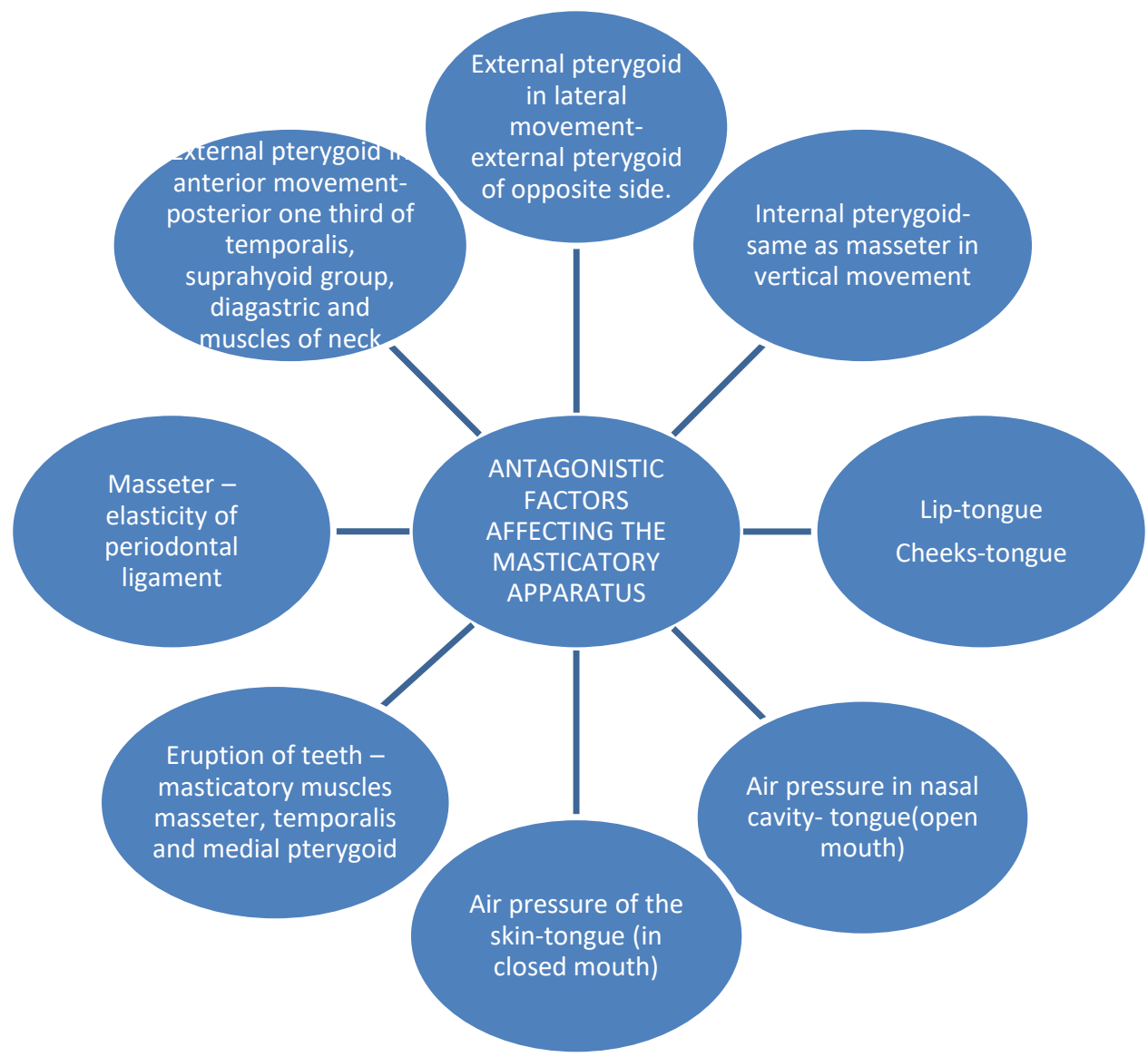

Some Antagonistic Forces Acting on the Masticatory Apparatus

\section{Mastication}

In infant, food is taken in first by suckling. During suckling, there is a rhythmic "carving in" of the cheeks, bobbing of the hyoid bone, snake like movement of the tongue, anterior mandibular thrust, sphincter like activity of the lips and an actual nodding movement of the entire head.

The classic suckle - swallow position in the newborn shows the head extended, tongue elongated and low in the floor of the mouth, jaws apart and lips pursed around the nipple. During deglutition, the rhythmic contraction of the tongue and facial muscles aids in the stabilization of mandible once the child starts taking solid foods. The pressure generated by chewing activity potentially could affect dentofacial development in two ways: greater use of jaws could increase the dimensions of the jaws whereas the lesser use leads to underdeveloped dental arches.

\section{Respiration}

Respiration, like mastication and swallowing is an inherent reflex activity. In infant it is carried out through the nose, with the tongue in proximity to the palate obturating the oral passage way. The mechanism of crying is intimately tied up with respiration and the laryngeal and pharyngeal co- ordination of muscles is seen quite early. Development of respiratory spaces and maintenance of airway are significant factors in orofacial growth. Mouth breathing appears to be simple but it will produce dynamic changes in the orofacial musculature. It can be due to obstructive, anatomic or habitual. The only reliable method of determining the mode of respiratory function is to use a plethysmograph (rhinomanometry) and air flow transducers to determine total nasal and oral air flow. The mirror test or water holding test can also be used.

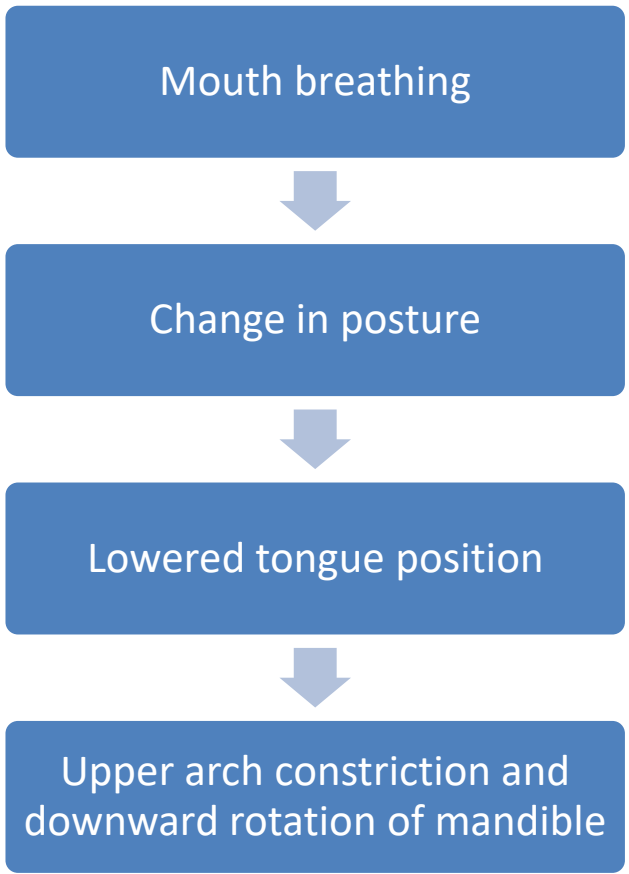

\section{Speech}

Unlike mastication, deglutition, and respiration which are reflexive in nature, speech is largely a learned activity dependent on the maturation of the organism. The muscles of the walls of the torso, the respiratory tract, the pharynx, the soft palate, the tongue, the lips and face and nasal passage ways are all concerned in the production of speech sound .The speech mechanism act on the breath stream in a number of ways, controlling the air mechanism, air direction, air flow, air release, air pressure, general air path and 
lingual air path. These actions involve muscle groups and call for compensatory interaction if abnormality exists in one area.

\section{Posture}

Important role of the musculature in addition to mastication, deglutition, respiration and speech is that of posture. Even at postural resting position muscle is apparently in active function, maintaining a status quo of soft tissue and bony elements.

\section{Thumb sucking/ finger sucking/ non- nutritive digital sucking}

Thumb sucking is the most common oral habit and its prevalence is between 13 to $100 \%$ (Graber, T.M) [4] There is a relationship between the level of education in parents, the child nutrition and the sucking habit (Farsi NM, Salama FS, 1997) [5]. Orality in the infant is related to pre-genital organization and the sexual activity is not yet separated from taking of nourishment. Thumb sucking that appears during first weeks is related to feeding problems. Some children use it as a teething device during the eruption of primary molar. In general they are related to hunger, satisfying of sucking instinct, insecurity or even a desire to attract attention. Some of children who do not stop this habit, will give it up when their permanent teeth erupt, but there is a tendency for continuing the sucking habit even until adult life (Johnson ED, Larson BE, 1993), (Van Norman RA, 1997)[6,7].

Thumb sucking is of 2 types:

1) Active: In this type, there is a heavy force by the muscles during the sucking and if this habit continues for a long period, the position of permanent teeth and the shape of mandible will be affected (Brash J, 1929) [1].

2) Passive: In this type, the child puts his/her finger in mouth, but there is no force on teeth and mandible, so this habit is not associated with skeletal changes (Gale EN, Ager WA, 1979) [8].

Sequelae of Thumb Sucking
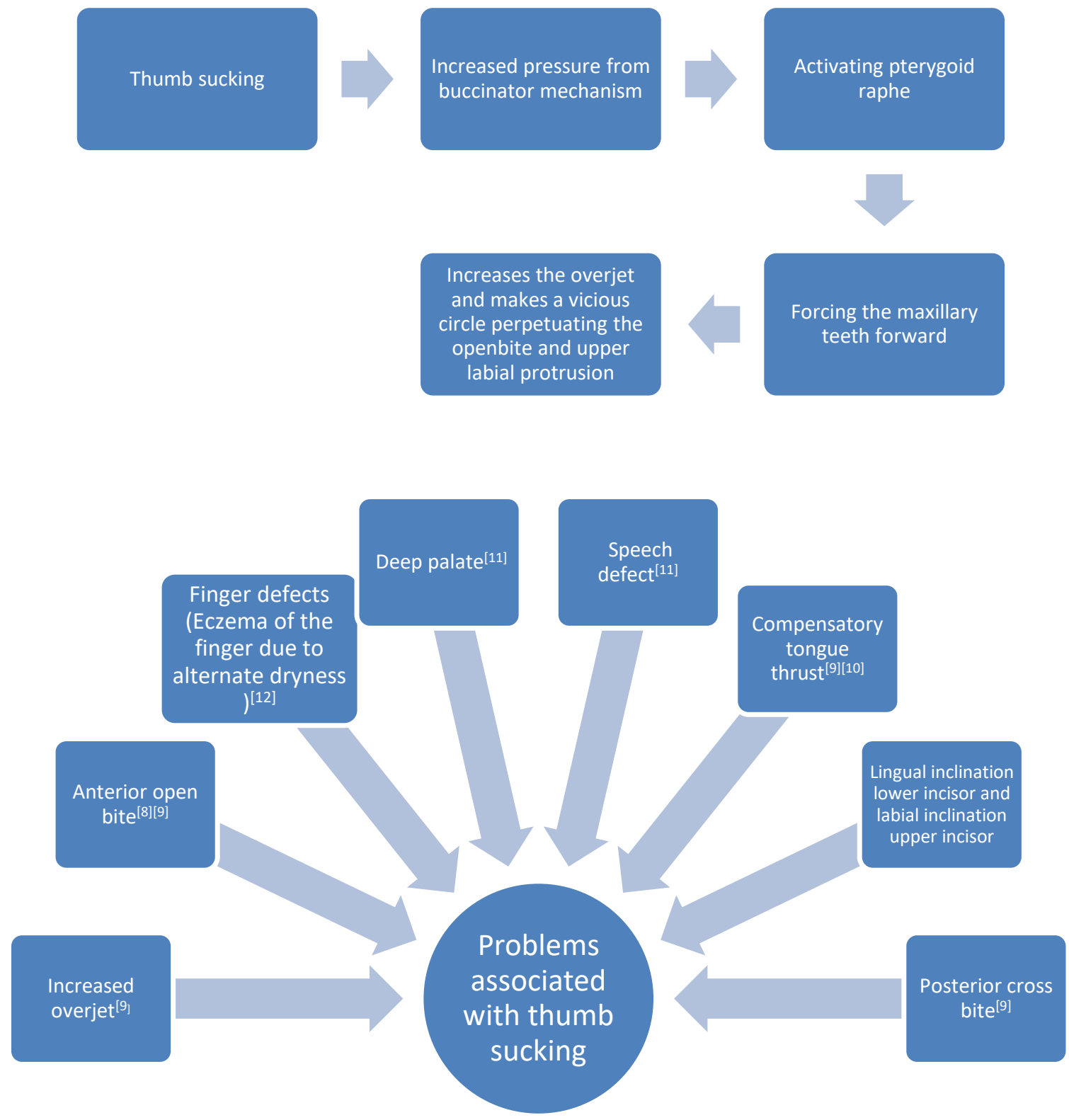


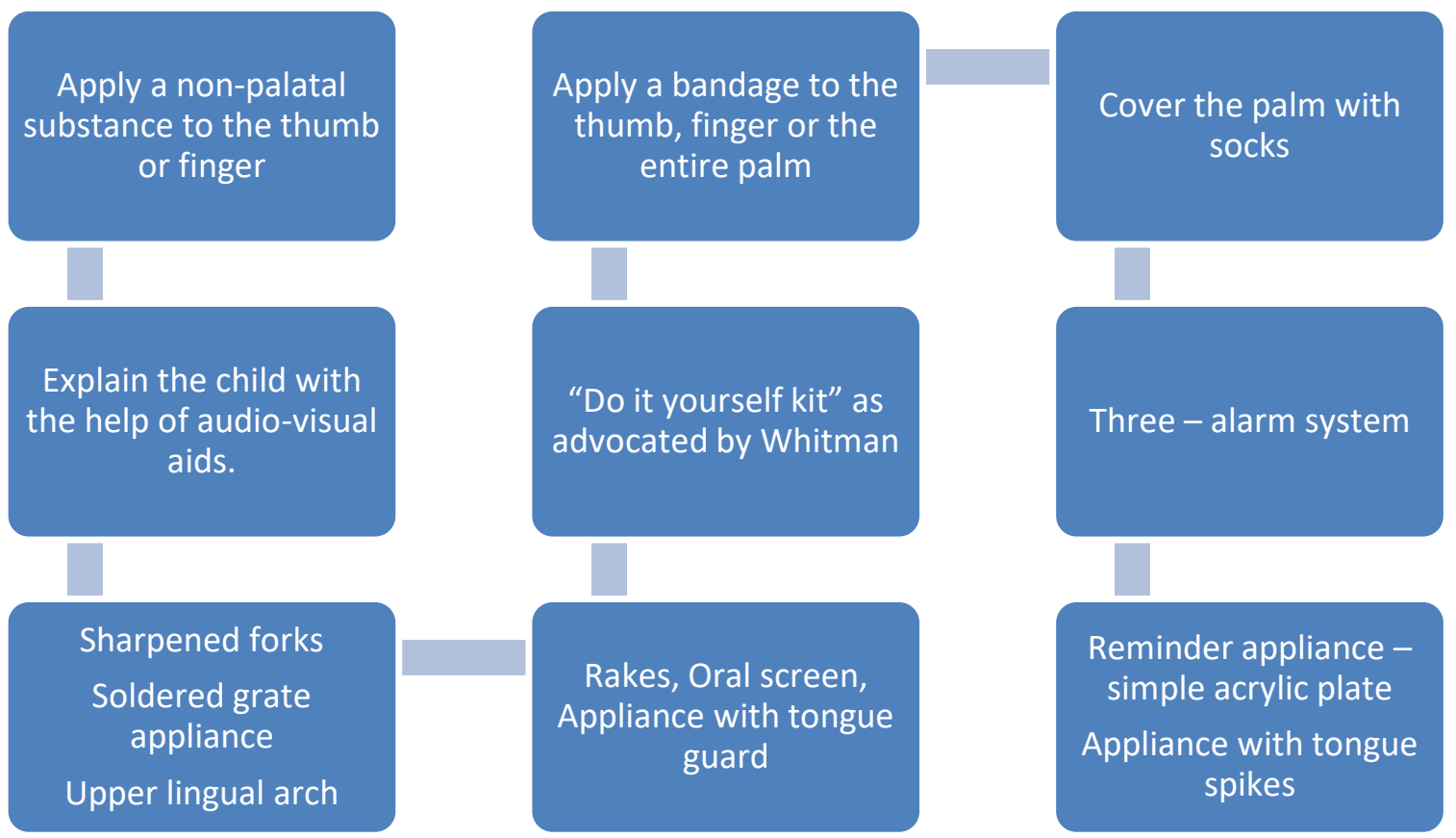

Various Measures Used For Correcting the Thumb Sucking Habit

\section{Tongue thrusting habit}

Many studies have demonstrated that tongue thrusting, also known as visceral swallowing or infantile swallowing, plays a significant role in the etiology of orofacial deformities(Graber T M, 1963) [13] [14]. Tulley W J, 1969[23] - states that tongue thrust as the forward movement of the tongue tip between the teeth to meet the lower lip during deglutition and in sounds of speech.

The tongue of the neonate is quite restricted in its movements these being usually up and down. After 4 weeks, backward movement of the tongue becomes apparent and forms a trough in a rhythmic manner. Usually by the 5th year, the elevation of the mandible has progressed to the point of posterior molar contact on swallowing with the tongue placed behind the maxillary incisors and lips relaxed.

The characteristic infantile or visceral swallow was correctly listed by Moyer's as the jaws are apart, with the tongue between the gum pads. The mandible is stabilized primarily by contraction of the muscles of the 8th cranial nerve and the interposed tongue. The swallow is guided, and to a great extent controlled by sensory interchange between the lips and the tongue.

Orthodontists can easily notice the difference in tongue movements between a mature swallower and a tongue thrust swallower. However, a quantitative and qualitative diagnostic method for differentiating the two swallowing patterns has rarely been reported (Chien-Lun Peng, Paul-Georg) [15].

\section{BRUXISM}

The term bruxism is derived from the French "La Bruxomanie" suggested by Marie and Piet Kiewicz in 1907. It is commonly defined as "gnashing and grinding of the teeth for the nonfunctional purposes". Bruxism is mainly regulated centrally and influenced peripherally. Sleep bruxism in the adult occurs during first and second stages of non-rapid eye movement (NREM) sleep and REM sleep (Okeson JP, 1998) [16]. Sleep bruxism has 2 types: Primary or idiopathic and secondary or iatrogenic. The first type is without any medical reason and the secondary type is whether with use of drug or without the use of drug (Kato T et al, 2001) $[17,18]$. Bruxism can cause permanent damage in the stomatognathic system, such as dental wear, TMD, or alterations in head posture(Velez AL, Restrepo CC, Peláez A, et al, 2007) [19].
Strong controversy exists concerning the treatment of bruxism in children. Whether to treat bruxism during childhood is still a matter of debate (Molina OF et al, 2000) [20]. There is no agreement regarding the effectiveness of therapeutic options, and the available scientific studies are not comparable to evaluate efficacy. The available treatment options include Occlusal splints and occlusal adjustments are usually sufficient to deprogramme the existing muscular pattern.

\section{Lip biting and lip sucking habit}

Lip sucking may occasionally develop a variant or substitute for thumb or finger sucking. This problem happens almost in all cases in inferior lip (Vogel LD, 1998).[12]

The first motion of the act consists of wetting the lips with the tongue, the lower lip is turned inward and tongue goes back into the mouth. As the tip of the tongue passes the incisal edges of the maxillary incisors, the lower lip is caught between maxillary and mandibular teeth and pressure is exerted as the lip slowly returns to its original position. The force produced by the lip as it slides around the teeth moves maxillary incisor labially and mandibular incisors lingually. The deformity reaches maximum when discrepancy between maxillary and mandibular incisors become equal to the thickness of the lower lip.

This habit is related to dryness and inflammation of lip and in severe cases will cause vermilion hypertrophy and in some people can cause chronic cold sore or lip crack (Ghanizadeh A, 2008), (Dahan JS et al, 2000) [21][22].

\section{Frenum thrusting}

If the upper permanent incisors are spaced slightly apart, the child may lock his labial frenum between these teeth and permit it to remain in this position for several hours. This habit probably starts as idle play but may develop into a tooth - displacing habit by keeping the central incisors apart, the effect being similar to that produced in instances by an abnormal frenum. This habit is rarely seen. 


\section{Pillowing habits}

Postural defects during the sleep have been considered as an etiologic factor in malocclusion. Children and adults do not lie in one position during sleep, but move about at frequent intervals, these movements are involuntary and are produced by nervous reflexes inorder to obviate pressure interference with circulation. Deformity, flattening of the skull and the facial asymmetry may occasionally develop during the first year in infants who habitually lie in supine position with the head turned towards right or left.

\section{Nail biting}

Nail biting usually develops after the sucking age i.e after 3 yrs of age. Frequently a child will go directly from the thumb sucking stage into the nail biting stage. It has been estimated by studies in the armed services that about $80 \%$ of all individuals are nail biters. It does not assist in the production of malocclusion since the forces or stresses applied in nail biting are similar to those in the chewing process. However in certain cases of nail biting where girt remains under the nails, a marked attrition of the lower anterior teeth, crowding and rotation have been observed. It is not a socially acceptable habit and is a normal tension release.

Onychophagy is a nail disease caused by repeated injuries of nails. The need to bite or eat fingernails is related to a psycho emotional state of anxiety. A nail biting child is exhibiting an evolutionary disturbance related to the oral stage of psychological development (Pearson GHJ, 1948) [24].

\section{Self - mutilation / self-injurious habits}

Self-mutilation, results in physical damage to the individual, and is extremely rare in the normal child. However, the incidence of self-mutilation in the mentally retarded population is between 10 and $20 \%$. Self-mutilation is a learned behavior which manifests biting of the lips, tongue and oral mucosa. Any child who willfully inflicts pain or damage to himself should be considered psychologically abnormal. Such children should be referred for psychological evaluation and treatment. Self-mutilation has also been associated with disorders, such as Lesch-Nyhan and Large's syndromes.

\section{Conclusion}

Abnormal pressure habits changes the alveolar bone and regulate teeth because the bone-building cells on the receiving end of pressure or stimulus cannot differentiate whether that pressure or stimulus is intentional or unintentional. The face, with its cartilaginous bone, yields easily to stimulus and pressure, especially during growth spurts, and presents the most complicated growth problem in the entire skeleton. Since the greatest growth changes in the head are being made by the facial structures, it logically can be assumed, therefore, that all abnormal pressures should be kept from this most vulnerable target, the face.

\section{References}

[1] Brash J. C. The aetiology of Irregularity and Malocclusion of the Teeth, London. Dental Board of the United Kingdom Lectures. 1929; p. 212.

[2] Bear PN, Lestor M. The thumb, the pacifier, the erupting tooth and a beautiful smile. J. Pedodontics. 1987; 11(2): 115-119.

[3] Finn SB. Clinical pedodontics, W B Saunders, Philadelphia. 1998; 370-80.

[4] Graber, T.M: Orthodontics Principles and practice

[5] Farsi NM, Salama FS. Sucking habits in Saudi children: Prevalence, contributing factors and effects on the primary dentition. Pediatr. Dent. 1997; 19(1):28-33.
[6] Johnson ED, Larson BE. Thumb sucking: Classification and treatment. J. Orthod. 1993; p 322-398.

[7] Van Norman RA. Digit-sucking: A review of the literature, clinical observations and treatment recommendations. Int. J. OrofacialMyol. 1997; 23: 14-34.

[8] Gale EN, Ager WA. Thumb sucking revisited. Am. J .Orthod. 1979, 55(2b): 167-170.

[9] Yemitan TA, daCosta OO, Sanu OO, Isiekwe MC. Effects of digit sucking on dental arch dimensions in the primary dentition. Afr. J .Med. Sci. Mar. 2010; 39(1): 55-61.

[10] Warren JJ, Levy SM. Pacifier use and occurrence of otitis media in the first year of life. Pediatr. Dent. 2001; 23(2): 103-107.

[11] Bishara SE. Textbook of orthodontics, 1st ed. USA: Saunders. 2001; pp. 250-251

[12] Vogel LD. When children put their finger in their mouths, should parents and dentists care? J. Dentistry. 1998; 64(2): 48-58.

[13] Graber TM. The "three Ms:" muscles, malformation, and malocclusion. Am J Orthod. 1963; 49:418-50. https://doi.org/10.1016/00029416(63)90167-2.

[14] Bruckl H, Trager E. Untersuchungen ü ber Art und Häufigkeit anormaler Schluckgewohnheiten. Fortschr Kieferorthop. 1962; 23:197-202. https://doi.org/10.1007/BF02170161.

[15] Chien-Lun Peng, Paul-Georg. Comparison of tongue functions between mature and tongue-thrust swallowing - An ultrasound investigation. American Journal of Orthodontics and Dentofacial Orthopedics; Volume 125, Number 5.

[16] Okeson JP. Management of temporomandibular disorder and occlusion. 1998; 4th ed.USA: Mosby. pp. 349-80

[17] Kato T, Thein NMR, Montplaisir JY, Lavigne GJ. Bruxism and orofacial movements during sleep. Dent. Clin. North Am. 2001; 45(4): 651-676

[18] Negoro T, Briggs J, Plesh O, Nielsen I, Mc Nell C, Miller AJ. Bruxism patterns in children compared to intercuspal clenching and chewing as assessed with dental models, electromyography and incisor jaw tracing: Preliminary study. ASDC J Dent Child. 1998; 65: 449-458

[19] Velez AL, Restrepo CC, Peláez A, et al. Head posture and dental wear evaluation of bruxist children with primary teeth. J. Oral Rehabil. 2007; 34:663-670. https://doi.org/10.1111/j.13652842.2007.01742.x.

[20] Molina OF, dos Santos Junior J, Nelson SJ, Nowlin T. Profile of TMD and bruxer compared to TMD and non-bruxer patients regarding chief complaint, previous consultations, modes of therapy, and chronicity. Cranio 2000; 18:205-219. https://doi.org/10.1080/08869634.2000.11746134

[21] Ghanizadeh A. Association of nail biting and psychiatric disorders in children and their parents in a psychiatrically referred sample of children. Child. J. Adolesc. Psychiatr. Ment. Health. 2008; 2(1):1. https://doi.org/10.1186/1753-2000-2-13.

[22] Lelong BA, Celant S, Leysen V. Oral perception in tongue thrust and other oral habits. Am. J. Orthod. Dentofacial Orthop. 2000; 118:385-91 https://doi.org/10.1067/mod.2000.109101.

[23] Tulley WJ. A critical appraisal of tongue-thrusting. Am J Orthod. 1969; 55:640-50 https://doi.org/10.1016/0002-9416(69)90040-2.

[24] Pearson GHJ. The psychology of finger sucking, tongue sucking and other oral habits. Am J Orthod. 1948; 34:589-98. https://doi.org/10.1016/0002-9416(48)90157-2. 